Original Research Paper

\title{
Psychological Approach of the Minors' Legal Status During Their Incarceration in the Romanian Detention Centers
}

\author{
Daniel M. Assad \\ CED Centre Europe, Romania
}

Article history

Received: 10-09-2019

Revised: 18-11-2019

Accepted: 04-12-2019

Email: lepaxdoitreipatru@yahoo.ro

\begin{abstract}
The issue of the convicted minors' legal status viewed from a psychological perspective is one of topical interest in the penitentiaries for minors in Romania. Minority is thus considered not just from a legal point of view, but also from a psychological one because a crisis over this topic is currently passed in Romania. The de facto situation is emphasized in all the specific institutions which have as an objective the re-education of convicted minors. The current paper highlights certain arguments in order to expand the informational spectrum of the state institutions who serve the purpose of promoting and developing special programs for minors' social reintegration during their period of incarceration. From this point of view, the paper focuses on the implementation of these standardized programs, but also evaluates equally the potentiality law enforcement offers in supporting those who execute a deprivation of liberty penal punishment. Are the Romanian authorities able to manage this situation? Are there enough instruments implemented to support the incarcerated minors? These are questions which deserve adequate answers.
\end{abstract}

Keywords: Judicial Status, Juvenile Liability, Juvenile Penitentiary, Minors Convicted, Psychological Approach

\section{Introduction}

The legal status of minors incarcerated in detention centers in Romania is a topic of high interest among the Romanian authorities. The psychological approach to this group of people deprived of liberty must concern the national authorities as the number of juveniles committing offenses has significantly increased in the last decade.

The Romanian authorities have intensified the fight against criminality since the country's adhesion to the European Union on the $1^{\text {st }}$ of January 2007 (Magherescu, 2019: 44). This membership status has opened de facto the way of an equilibrium in achieving competences in the juridical field in particular in criminal matters.

In the current context, the judicial mechanisms must be imperatively corroborated with psychological instruments in order to realize the thorough concordance between contemporary society's needs and the psychological side of the individuals. An individual approach to the psychological side is considered to have a positive influence over the effectiveness of the purpose of the penal trial.

From this point of view, it is appreciated that those psychological aspects cannot be analyzed unitary, independent of the judicial ones, but instead they coexist within an integrated unit. Thus, the psychological approach towards the legal status of convicted minors during their incarceration appears to be a necessity within the current legal framework. This necessity is challenged by the need for strict delimitation of the two constitutive elements of the same mechanism - criminal justice.

Moreover, addressing the issue regarding how the governmental programmes using which the psychological approach are implemented is the main purpose of this article. It also focuses on finding answers to the most important questions. In the research paper some arguments and proposals de lege ferenda are advanced having as their main purpose improving the legal framework in the matter of solving the minors' needs by means of psychology during their incarceration in the detention centers of Romania. All these aspects are stated in order to facilitate the approaches of judicial authorities involved in the detention centers for minors in their efforts towards the social reintegration of convicted minor.

Minority cannot be thus viewed as a drawback and a difficult situation for the judicial authorities to manage, but rather a transitional situation and an issue extreme 
importance for achieving justice in criminal matters. For this reason, both the psychological and judicialpsychological aspects of minors open up an appropriate way of realizing their scope.

It must be highlighted that the psychology of convicted minors who receive a penal punishment and are deprived of liberty has a major role at the macrosocial level, its size being exemplary.

At the international level, the corpus of rules on minors represents a step forward within the reform process promoted by the UN Organization regarding convicted minors. The Beijing Rules (United Nations, 1985) have also been mentioned in the preamble of the Convention on Rights of the Child of 1989 (United Nations, 1989). It is recommended that in all decisions on minors the issue of the minors' best interest must be taken into account.

\section{Methodology}

In carrying out the current paper, the classical methods of research have been used. They consists in evaluation of legal provisions into force in cases of minor offenders along with referential jurisprudence decisions adopted by the courts of law in Romania. The literature on the topic involved also supported the study from a theoretical expectation.

The research paper is not the result of an empirical research work, as a consequence it neither contains nor generates empirical data from public institutions or private organization in the area of juvenile justice.

The current research paper is a conceptual approach to the topic of the psychological issues of minors incarcerated in detention centers in Romania. In addressing this topic, the following aims have been established:

i. To conduct research on the psychological issue in the most significant detention centers of minors in Romania.

ii. To present both the goals and drawbacks the local judicial authorities are confronted with.

iii. To discuss the concept of aggression developed among minors incarcerated and how the law enforcement works in close cooperation with psychologists in purpose to solve the situation.

iv. To propose de lege ferenda proposals in order to improve the current situation currently met in the detention centers for minors in Romania.

\section{Minority and Penal Law}

In researching the issue regarding implementing solutions in cases of incarcerated minors in detention centers in Romania, it is very important to take into account the penal law and the legal provisions which regulate their legal status knowing that the legislator has provided increased attention toward minors being considered vulnerable people.

Thus, due to their lesser physical and mental development, minors who commit an offence are criminally liable for their behaviour conditionally under the Penal Code provisions (Law no. 286 of 2009).

From the penal law perspectives, minority appears as an atypical situation of achieving justice in criminal matters. The substantive penal law has offered a general framework on regulating minority during the penal trial in Romania. The legislator established three categories of criminal liability for the minor perpetrator. These are based on the minor's age at the moment of committing the offence. The first category is related to the minors up to 14 years old, the second category to the minors aged between the 14 and 16 years old and finally the third to those minors over 16 years old.

Thus, in accordance with Article 113 of Penal Code the criminal liability of minors up to 14 years old cannot be engaged due to the fact that the minor does not have such liability. This means that the judicial bodies cannot take any punitive measures from the penal law point of view with this minors.

However, minors aged between 14 and 16 years old can be subject to penal liability, the penal law provides a conditional criminal liability, which depends on the existence of discernment at the moment of committing the offence. From this point of view, in order for the judicial bodies to reach the criminal liability threshold against a minor aged between 14 and 16 years, the existence of discernment of the minor at the moment of the committing offence is compulsory to be proven. The legislator established a relative presumption of the absence of discernment among this group of minors. Nevertheless, if the presumption is infringed the minor perpetrator will be the subject of criminal liability for the offence committed. Conversely, minor perpetrators who commit offenses without discernment will not be criminally liable. By definition, discernment is the minor's capacity to perceive the offense's social danger feature and to express consciously the desire, a capacity viewed not generally, but related to the concrete offence committed.

In accordance with the Penal Code, minors over the age of 16 are subject to criminal liability for the offenses committed. In such cases, the judicial bodies do not need to prove the existence of discernment because the legislator has imposed an absolute presumption on the existing discernment of this group of minors, in conformity with Article 113 (3) thereof.

It is obvious the situation is more complicated for the second category of minors, namely to those aged between 14 and 16 years. It is considered that in these cases the judicial authority is involved in order to establish criminal liability through psychology. This 
means that establishing the existence or absence of the minors' discernment is carried out by forensic medical experts in the area of juvenile psychology by disposing the psychiatric examination (Magherescu, 2017: 39-40).

Basically, both discernment and guilt are essential conditions for an offence. Discussing guilt in criminal matters, we are referring especially to discernment as an intrinsic element of the offence. A hypothesis states that discernment can exist without guilt, while guilt in criminal matters cannot exist without discernment. It concludes that a minor who commits an offence, but in the absence of discernment will not be the subject of criminal liability. The offence is by definition the penal action committed with discernment and provided for by penal law. Thus, regarding minors who commit offenses, two kinds of connections are established. One of these is between the discernment and offence, while the other is between the guilt and offence. This is because of the definition of discernment which states that it is the minor's capacity to realize the criminal intent of committing offenses, while the guilt represents the modus operandi itself. From this point of view, during the minor defendant's clinical examination, the psychologist expert will analyze the minor's deliberate action existed at the moment of committing offence. This refers to the wish of executing criminal action, its dangerous result as well as the manner in which the minor has perceived the result and accepted it.

For this reason, in order for the judicial bodies to achieve the criminal liability against minors aged between 14 and 16 years, the existence of their discernment at the moment of committing offence must be proven.

\section{Legal Status of Minor Condemned Definitively}

Committing offenses supposes releasing mechanisms provided by the judicial bodies in order to invoke criminal liability for those found guilty. Minor defendants in a penal case are not excepted from this rule. Nevertheless, as earlier stated the minors are protected by the penal law which regulates a special legal regime. In these circumstances, if the minor perpetrator is found guilty by the court of law then he a penal punishment will executed within the legal framework established by the legislation into force. From this point of view, the Penal Code of Romania regulates a special penal procedure for minors within Title V of Chapter I entitled "Regime of the minor's criminal liability" at Article 113-134 thereof.

Regarding the regime of executing criminal punishment, the Penal Code regulates a mixed regime consisting of educative measures non-deprived of liberty and educative measures deprived of liberty. For the current paper, only the second category of penal sanctions applied to minors presents interest. Among these measures, the Penal Code regulates the incarceration in an educative center and incarceration in a detention center.

The difference between the two categories of penal sanctions applied to condemned minors is that in the first case the minor is incarcerated in an establishment specialized in the rehabilitation of minors who committed offenses. The center will provide the minors a school preparatory program and educational specialization in accordance with its abilities as well as programs for social reintegration, in accordance with Article 124 (1) Penal Code. These programs will help minors at the end of the period of executing educative measures as criminal sanction applied by the court of law.

The second sanctioning measure of penal law stated by the court of law is that of minor incarceration in a detention center. This consists of the minor's incarceration in a specialized establishment for minors' rehabilitation under surveillance which offers intensive programs of social reintegration and professional specialization in accordance with the minor's abilities.

A new circumstance arises during the execution of educative measure in cases of a new offence committed. Thus, the situation of post-condemnation of the second offence is frequently met in the psychologists' practice, while facing serious forms of disturbance of minors who execute punishments deprived of liberty (de Vries et al., 2018: 3642-3656).

If the minor condemned commits a new offence during the executing phase of penal trial or is judged for another offence committed in a set of circumstances, the court of law prolong the incarceration in accordance with the punishment regulated by the penal law.

\section{The Issue of Minor's Personality and the Psychology Challenges}

\section{Elements of Minors' Personality}

In adhering to the legal framework and implementing the system of the convicted minor's re-education, the investigation of psychic processes based on the minor's behaviour according to the particularities of these processes due to their age as well as the diverse possibility of influencing have been taken into account (Sijtsema et al., 2019: 1354-1362). Doctrine has pointed out "The issue of human personality currently constitutes the topic of several scientific research studies aimed at identifying the psychic processes which explain human behaviour including the minor convict's behaviour" (Brezeanu, 1998: 97-103).

In fact, understanding the minor's behaviour is useful for the psychologist expert (Grubbs et al., 2019: 2-5) who will analyse both current and previous aspects of it in order to better understand their likely future behaviour. 
From the psychology researchers' perspective, the theory is based on the idea that the judicial bodies must not to focus their attention on the minor as an offender, but as a human being. Moreover, they must view the minor as a personality liable to change to identify, under such an analysis, the most efficient ways of influencing them and enabling rehabilitation.

In these circumstances, minor delinquents are still at the stage of developing their personality and for this reason they are responsive and sensitive to social environmental factors (Mulraney et al., 2019: 1-4). As a consequence, the necessity of knowing the personality of incarcerated minors the re-educative system is activated. The re-educative system for convicted minors is not a new one implemented within the system of executing the criminal sanctioning of minors. This system is methodologically connected to the social reintegration one, both being knowledge processes.

The psychology science has certain challenges in the matter of convicted minors deprived of liberty. One of these is certainly the minor's social reintegration.

The issue of dual system of both re-education and reintegration is based on the concept of avoiding a possible failure of minors liberated from the rehabilitation center as well as its impact over their social life. Thus, the minors' psychological examination during the execution of educative measure deprived of liberty in purpose to become a person useful for society comes contrary to the other inadequate measures and actions of rehabilitation.

The evaluation of juvenile delinquency phenomenon supposes that the minor delinquent as the subject of reeducation process "must be reported alike to the provisions and pattern of personality advanced by society as well as to the real minor's possibilities of achieving one's personality" (Brezeanu, 1998: 38).

In this context, the pattern of personality is also involved in the area of researching psychology science being a field where the concept itself was and is still well-used. The convicted minors' personality appears as a bio-psycho-social phenomenon which characterizes their psychological side of personality through the process of social individual's introspection connected to the social objective reality.

\section{Hypothesis of Psychology in Cases of Minors}

Psychological examination is a form of evidence during the penal trial which helps judicial bodies to find the legal way of deciding over the minor's criminal liability. From this point of view, the psychologist expert is entitled to address the following issues:

- The minor's psychic state

- Whether the minor presents psychic disturbance

- The minor's basic pathological state
- Observing the simulation/dissimulation and their form

- The minor's psychological features

- Observing the predisposition state to committing criminal actions

- Analyzing the minor's capacity for critical discernment

- Establishing the causality relation between the minor's psychological state and the action of committing the offence

Certain hypotheses arise in relation to the psychological valences in cases with minor offenders. One of these is that of simulated absence of discernment. The basic syllogism of criminal liability is characterized by the presence of discernment of perpetrators. From this point of view, in the practice of psychological expertise there are cases in which the minor tries to simulate the absence of discernment in order to obtain the exemption from criminal liability and avoid penal sanction.

The simulation is presented under several forms, some of them being less, while the other serious. The proper simulation, dissimulation and supra-simulation of a less illness that the minors overestimate belong to the last category. These forms are presented through crying, shouts, destroying goods, neurotic gestures, which are subsequently minimized till the renunciation to them completely.

Both violence and aggression are forms of manifestation most frequently met (Mauri et al., 2019: 1-6). In the long run it is possible for minor even to forget such gestures and finally expose itself to such simulation.

\section{Deflective Behaviour within the Detention Centers}

The minor's incarcerated state is a classical one within the detention centers in Romania. The situation degenerated in the last decade due to the congestion - an accountable phenomenon if it is taken into consideration the high level of criminality among the youth especially minors (Magherescu, 2014: 192-193). The judicial authorities' tendency is that of subsuming challenges at the local level to those imposed by the European standards directed by the European Convention of Human Rights and European Court on Human Rights' jurisprudence as a consequence of Romania's status as a member state of the European Council. Moreover, the rules in criminal matters are directed by the provisions adopted at the European Union level (Civil Liberties, 2017), due to Romania's obligation to adopt the community acquis even before 2007 (Magherescu, 2019: 44).

The convicted minors who execute a punishment deprived of liberty in detention centers could develop a syndrome which affects worst their mental health. The most frequent syndromes are panic disorder, anxiety 
disorder, which "is characterized by pervasive and uncontrollable worry about a variety of issues or events" (Hudson et al., 2019: 3-27).

In spite of the issues stated above, doctrine has been involved in finding solutions to the risk factors for youthful offenders (Kennedy et al., 2018: 177-190) associated to the prohibited substance consumption.

\section{Conclusion}

It is clear that the process of rehabilitation of convicted minors is a highly consequential one among the human personality processes. The minor delinquent's personality means the result of permanent and multiple reports of mutual conditioning as well as interdependence both among the defining features of a minor who committed offenses' personality and between its personality and concrete environmental conditions in which the minor is growing up and becoming prepared for society.

In this context, the family plays an essential role which exercises the first step in the process of the minor's education as a future adult (Sedgwick et al., 2019: 3). It has been observed that the minors who grow up in "socioeconomically disadvantaged families have greater rates of conduct problems compared to their more privileged peers" (Wertz et al., 2018: 54).

The concrete forms of executing penal punishments of minors are influenced by the society environment the minors grew up and live in. From this point of view, the solutions regulated by the legislator cannot be separated from the social realities and all the factors which determine the programs for convicted minor's rehabilitation. All these programs are provided in accordance with the state penal policy and its scope.

Taking into account the unclear situation at the national level in Romania regarding the penitentiary system of executing deprived of liberty punishments for convicted minors, certain proposals of de lege ferenda must be advanced, as follows:

1. Coordinating adequate programs which must improve current conditions for developing activities aimed at of the minor's rehabilitation within the penitentiary system

2. Implementing social and economic reforms aimed at diminishing and controlling the phenomenon of juvenile criminality

3. Adopting a state penal policy that is integrated into contemporary social values which should offer newer conditions of elaboration of legislative documents

Moreover, for a better supervising of minors, it is necessary to establish post-incarceration support centers either by the local authorities or NGOs. In these circumstances, the function of prevention would be more efficient for minors and they will not lose their childhood within the detention centers. This will also return into diminishing the cases of young offenders.

As a consequence, it could be observed that the protection of minors constitutes an essential element in the field of society protection being also related to all groups of offenses committed by minors (Magherescu, 2014: 196).

\section{Acknowledgement}

I would like to acknowledge the Journal of Social Sciences' Editorial Board members and the anonymous reviewers who approved my work and decided to publish it in the Special Issue. I also would like to address special thanks to my collaborators and volunteering team I am involving in during the summer time which consists in entertaining activities organized for minors.

\section{Funding Information}

There is no financial source provided for the article publishing process.

\section{Ethics}

There is no ethical issue and conflict of interest regarding the article published.

\section{References}

Brezeanu, O., 1998. Minorul si Legea Penala. 1st Edn., All Beck, Bucharest, ISBN-13: 9739876544, pp: 156.

Civil Liberties, 2017. European Parliament: Prison conditions in the Member States: Selected European standards and best practices. Civil Liberties. Briefing.

de Vries, S.L.A., M. Hoeve, J.J. Asscher and G.J.J.M. Stams, 2018. The long-term effects of the youth crime prevention program "new perspectives" on delinquency and recidivism. Int. J. Offender Therapy Comparative Criminol., 62: 1552-6933. DOI: $10.1177 / 0306624 X 17751161$

Grubbs, K.M., J.D. Broussard, E.L. Hiatt, M.A. BeasonSmith and E.J. Teng, 2019. Importance of knowledge in the behavioural treatment of panic disorder. Behav. Cognitive Psychotherapy, 47: 611-615: DOI: 10.1017/S135246581900002X

Hudson, J.L., J. Anagnos and V. Ingram, 2019. Phenomenology and Standard Evidence-Based Care of Anxiety Disorders in Children and Adolescents. In: Innovations in CBT for Childhood Anxiety, OCD and PTSD: Improving Access and Outcomes, Farrell, L., T. Ollendick and P. Muris (Eds.), Cambridge University Press, Cambridge, pp: 3-27. 
Kennedy, T.D., W.A. Edmonds, D.H. Millen and D. Detullio, 2018. Chronic juvenile offenders: Exploring risk factor models of recidivism. Youth Violence Juvenile Justice, 17: 1556-9330. DOI: $10.1177 \% 2$ F 1541204018770517

Law no. 286 of 2009 on the Penal Code of Romania, published in the Official Journal no. 510 of 24 July 2009, into force on 1 February 2014.

Magherescu, D., 2014. Mijloace legale de protectie a copilului in mediul agresiv contemporan. Proceedings of the International Conference on "Criminalitatea si Mediul", Apr. 11-11, Bucharest, Universul Juridic Publishing House, pp: 189-199.

Magherescu, D., 2017. Criminalistica. 1st Edn., Wolters Kluwer, Bucharest, ISBN-13: 978-606-677-025-5, pp: 312 .

Magherescu, D., 2019. Admission of guilt agreement as a special procedure of the penal trial - a particular attention upon the Romanian model. J. Soc. Sci., 15: 1558-6987. DOI: 10.3844/jssp.2019.44.57

Mauri, M.C., G. Cirnigliaro, C. Di Pace, S. Paletta and A. Reggiori et al., 2019. Aggressiveness and violence in psychiatric patients: A clinical or social paradigm? CNS Spectrums, 24: 564-573.

DOI: $10.1017 / \mathrm{S} 1092852918001438$

Mulraney, M., H. Hiscock, E. Sciberras, D. Coghill and M. Sawyer, 2019. Mental health difficulties across childhood and mental health service use: Findings from a longitudinal population-based study. Brit. J. Psychiatry, 27: 1-6. DOI: 10.1192/bjp.2019.32
Sedgwick, R., A. Duff, S. Lines, A. Akenzua and J. Fergal, 2019. Family-inclusive practice in a psychiatric intensive care unit. BIPsych Bull., 11: 1-5: DOI: 10.1192/bjb.2019.11

Sijtsema, J.J., C. Garofalo, K. Jansen and T.A. Klimstra, 2019. Disengaging from evil: Longitudinal associations between the dark triad, moral disengagement and antisocial behavior in adolescence. J. Abnormal Child Psychol., 47: 1573-2835. DOI: 10.1007/s10802-019-00519-4

United Nations, 1985. Standard minimum rules for the administration of juvenile justice ("The Beijing Rules") Adopted. General Assembly Resolution 40/33.

United Nations, 1989. Convention on the Rights of the child, adopted and opened for signature, ratification and accession. General Assembly Resolution 44/25.

Wertz, J., J. Agnew-Blais, A. Caspi, A. Danese and H.L. Fisher et al., 2018. From childhood conduct problems to poor functioningat age 18 years: Examining explanations in a longitudinal cohort study. J. Am. Jo. Child Adolescent Psychiatry, 57: 0890-8567. DOI: 10.1016/j.jaac.2017.09.437 